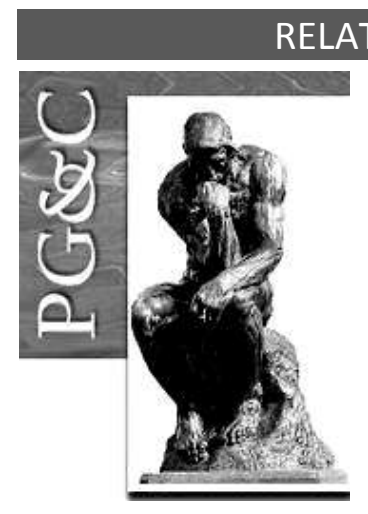

\title{
ANÁLISE DAS PRINCIPAIS LOJAS DE COMÉRCIO ELETRÔNICO DO PAÍS SOB A ÓTICA DO MARKETING DIGITAL NAS REDES SOCIAIS VIRTUAIS
}

\author{
Monize Sâmara Visentini \\ Doutora em Administração pela Universidade Federal do Rio Grande do Sul, \\ Brasil. Professora da Universidade Federal da Fronteira Sul, Brasil. \\ E-mail: monize.visentini@uffs.edu.br
}

Liara Laís Scheid

Bacharela em Administração pela Universidade Federal da Fronteira Sul, Brasil.

E-mail: liarascheid@yahoo.com.br

Fernanda Bard Chagas

Bacharela em Administração pela Universidade Federal da Fronteira Sul, Brasil. E-mail: fernandabard@hotmail.com

\begin{abstract}
Resumo
As mídias sociais proporcionam a aproximação da empresa com o cliente, divulgação e vendas de produtos. Entretanto, são escassas as investigações no país que avaliam as estratégias que as empresas de CE adotam para um relacionamento dentro das redes sociais virtuais. Este estudo visa descrever as atividades desenvolvidas por importantes empresas de comércio eletrônico dentro das fanpages do Facebook e identificar o engajamento dos usuários para com essas atividades desenvolvidas nas redes de relacionamento, assim como verificar quais atividades geram maior engajamento por parte dos clientes A pesquisa é do tipo descritiva e quantitativa, e utiliza a técnica de observação sistemática direta das fanpages. Á rede social virtual a ser monitorada é o Facebook, tendo em vista o grande número de usuários que possuí. Os resultados do estudo indicam que, diante das atividades exercidas pelas lojas no Facebook, as imagens aparecem como a ferramenta mais utilizada, seguida dos links. Quanto ao conteúdo das postagens, nota-se que estes variam de acordo com o foco das empresas. No que tange ao engajamento do usuário com a loja, observou-se que as taxas de curtidas são superiores às de comentários, o que pode indicar que os usuários buscam atividades que exijam menos esforço de sua parte quando utilizam as redes sociais. Diante disso, concluí-se que a variável "fãs" não representa ser um fator determinante para a criação de engajamento, mas sim, a comunicação e a interação com os usuários detêm relação direta no retorno das fanpages.
\end{abstract}

Palavras-chave: Comércio Eletrônico. Redes Sociais Virtuais. Facebook. Engajamento virtual.

\section{ANALYSING THE MAIN BRAZILIAN E-COMMERCE STORES ON A DIGITAL MARKETING VIEW ON THE VIRTUAL SOCIAL NETWORKS}

\begin{abstract}
Abstrat
Social media provide the company to approach with its customers, also, allow the promotion and sales of its products. However, national investigations that evaluate the relationship strategies that the CE companies adopt within the virtual social networks are scarce. This study aims to describe the activities developed by important e-commerce companies within the Facebook fanpages identify the users' engagement with these activities developed in the relationship networks, as well as to verify which activities generate greater engagement on the part of the customers. The research is classified as descriptive and quantitative survey and was conducted through the systematic and structured observation technique. Facebook was the monitored virtual social network, in view of the large number of your users. The results indicate that, on the activities carried out by stores on Facebook, the images appear as the most used, followed by links. As for the content of posts, we noted that these vary according to the focus of companies. With respect to user engagement with the
\end{abstract}

Perspectivas em Gestão \& Conhecimento, João Pessoa, v. 8, n. 1, p. 67-85, jan./abr. 2018.

DOI: http://dx.doi.org/10.21714/2236-417X2018v8n1p67.

http://periodicos.ufpb.br/ojs2/index.php/pgc. ISSN: 2236-417X. Publicação sob Licença (cc) EY-NC-ND 
store, it was observed that enjoy rates are higher than comments, which may indicate that users seek activities that require less effort on your part when using social networks. Thus, it was concluded that the variable "fans" does not represent a determining factor for the creation of engagement, but rather, communication and interaction with users have a direct relationship in the return of fanpages.

Keywords: E-commerce; Virtual Social Networks; Facebook; Virtual Engagement.

\section{INTRODUÇÃO}

A evolução do comércio eletrônico (CE) como canal de compras tem motivado as empresas virtuais a desenvolver estratégias competitivas (ANDRADE; SILVA, 2017), a fim de buscar uma maior aproximação dos seus consumidores. Dentre essas estratégias, pode-se destacar o engajamento através das redes sociais, por meio das fanpages, como premissa de interagir mais abertamente ao público. O engajamento virtual pode ser definido como uma manifestação comportamental dos consumidores para uma marca ou empresa que vai além do comportamento de compra (VAN DOORN et al., 2010), impondo elementos como diálogo, interação e sentimento, ou seja, trata-se de um envolvimento, que vai além do número de seguidores em uma rede social ou likes em uma postagem.

Para Sedley (2008), o engajamento pode ser considerado um fator de criação e manutenção de relacionamento entre as organizações e respectivos consumidores, além de uma fonte consistente de vantagem competitiva. Além disso, cada vez mais, as pessoas estão se voltando umas para as outras na tentativa de obter informações imparciais e apuradas; logo, os consumidores buscam ajuda on-line para partilhar opiniões sobre produtos de todos os tipos (LIMA; NUNES, 2015)

Essa migração para o on-line tem relação com o aumento significativo do uso da internet entre os usuários brasileiros (MUSSUCHIN; TAVARES, 2016). Observa-se que o tempo gasto nas redes aumentou consideravelmente nos últimos anos. De acordo com a Pesquisa Brasileira de Mídia (PBM, 2014), $48 \%$ dos brasileiros utilizam a internet, sendo que $37 \%$ acessam a rede diariamente. Outro dado relevante, diz respeito à utilização das redes, no qual $67 \%$ dos usuários freqüentes afirmam que a usam para consumir notícias e se informar. O Facebook aparece como a rede mais utilizada, com $83 \%$ da preferência.

O Brasil é o país que possui o segundo maior número de usuários do Facebook, atingindo um percentual de $28 \%$ os quais sinalizam aproximadamente 56 milhões de brasileiros que utilizam a plataforma (SOCIALBAKERS, 2012). Em análise, a influência do Facebook se mostra cada vez maior, isso reforçado por alguns elementos significativos na trajetória da rede, como por exemplo, a obrigatoriedade da "Linha do Tempo", no ano de 2012, inclusive para as empresas. Com isso, a rede passou a exibir os anúncios entre as publicações de amigos e de páginas que os usuários seguiam; logo, abarcou-se que de $85 \%$ dos U\$\$ 3,7 bilhões que o Facebook arrecadou em 2011 vieram da publicidade (GLOBO.COM, 2014).

Esses dados apontam a dimensão que as redes sociais têm alcançado, principalmente pela sua capacidade de transmitir de "muitos para muitos" em uma escala global. As empresas devem reconhece o poder que a internet e mídia social representam, pois além de ampliar as formas de influenciar clientes, essas plataformas possibilitam eliminar barreiras geográficas e distâncias físicas, assim como representam um baixo custo-benefício e, sobretudo, possuem uma ampla capacidade de criar valor tanto aos consumidores quanto, e principalmente, às próprias empresas (OVIEDO-GARCÍA et al., 2014).

Este trabalho visa descrever as atividades desenvolvidas por importantes empresas de comércio eletrônico dentro das fanpages do Facebook e identificar o engajamento dos usuários para com essas atividades desenvolvidas nas redes de relacionamento, assim como verificar quais atividades geram maior engajamento por parte dos clientes. A pesquisa foi desenvolvida no período de cinco meses, sendo que foram selecionadas três lojas brasileiras de comércio eletrônico para o

Perspectivas em Gestão \& Conhecimento, João Pessoa, v. 8, n. 1, p. 67-85, jan./abr. 2018. 
estudo, as quais estão entre as cinco melhores do ranking Reclame Aqui (2014). Buscou-se observar todas as postagens durante o período estipulado nas páginas do Facebook das três lojas. Diante da observação, analisaram-se as tipologias e as características das atividades desenvolvidas e de que formas as publicações promoveram a interação com os usuários.

Faz-se importante o entendimento das atitudes do consumidor que com acessibilidade móvel à web e conectividade em mídias sociais, compartilham suas experiências de compra e incrementam o m-commerce e grupos de compras coletivas (TELLES, 2010). O monitoramento contínuo de ações mercadológicas contribui no mapeamento do perfil e das mudanças no comportamento do consumidor, possibilitando o estabelecimento de estratégias digitais. Essas, por sua vez, "consolidam o engajamento, alavancando a interatividade e a experiência, como principal aspecto para o sucesso de estratégias de marketing" (OKADA, 2011, p. 3).

Para as empresas, o engajamento "viraliza" conteúdos e, consequentemente, o nome de uma marca e/ou uma empresa; por conseguinte, passa a disseminar opiniões de quem já experimentou um produto ou serviço para outros consumidores; logo, permite a cocriação e a experiência de valores. Soares e Monteiro (2013, p.10) destacam que as interações posicionam-se como "grande fator a auxiliar na divulgação da página, bem como o nível de engajamento dos usuários relativamente às publicações da página." Para os autores, essa preposição reforça-se a importância do engajamento, pois à medida que o nível de engajamento dos usuários aumenta, têmse um acréscimo na quantidade de interações promovidas, aproximando cada vez mais o usuário da empresa.

\section{AS REDES SOCIAIS E O ENGAJAMENTO VIRTUAL}

O rápido crescimento das redes sociais, que tem sido observado ao longo dos últimos anos, é um indicativo da sua entrada como cultura dominante e cotidiana na vida de muitas pessoas (OFCOM, 2008). Para Fialho (2014), as redes sociais são a manifestação cultural, a tradução em padrão organizacional, duma nova forma de conhecer, pensar e fazer política e de definir estratégias. Para Fialho (2014, p. 11), essas redes fortaleceram-se como "ferramentas de aprendizagem e divulgação da informação em contexto organizacional, constituindo novas formas e ferramentas de facilitação da gestão colaborativa e cooperativa". O consumidor deixa de ser um mero expectante de ações de marketing, e passa a ser, cada vez mais, um participante pró-ativo e interativo com os processos, em busca da criação de valor (SHAWHENEY et al., 2005).

Outra questão a ser destacada no uso das redes sociais como ferramenta de comunicação é quanto aos benefícios que essas proporcionam para as organizações. As redes sociais representam baixo custo de criação e manutenção, se considerado seu custo-benefício; isso devido à grande dimensão que seu conteúdo atinge, inibindo barreiras e distâncias físicas, além da enorme quantidade de informações que podem ser disseminadas por essa via (OFCOM, 2008). Outro aspecto relevante trata-se da facilidade de direcionamento de dados para um público específico, diferentemente dos canais tradicionais de comunicação.

Diante das inúmeras ferramentas tecnológicas existentes, Rapp et al. (2013) apontam que os integrantes das redes sociais as usam para interagir com amigos e familiares, de modo a ver e compartilhar fotos e vídeos, como também as utilizam para buscar oportunidade de negócios no mercado e/ou informações sobre marcas e empresas. Esses autores ainda mencionam um dado relevante na configuração dos novos consumidores online, na qual mais da metade dos usuários interagem com as marcas que consome através das redes sociais.

As redes sociais facilitam e auxiliam na disseminação da informação, levando os usuários a participar do processo de divulgação. Em consonância, para Dacol et al. $(2014$, p. 06) as redes sociais virtuais são conexões "recheadas por pessoas ligadas entre si, gratuitamente, que produzem um grande volume de informações". Dentro desse contexto, têm-se a importância do termo engajamento como fator determinante na mídia social; onde segundo Sedley (2008 apud LIMA; NUNES, p. 01, 2015), 
o principal ponto é que o engajamento pode ser considerado um "fator de criação e manutenção de relacionamentos entre as organizações e respectivos consumidores", além de ser um meio sólido de vantagem competitiva perante concorrentes.

No campo econômico, a exploração do nicho social networking vem sendo alvo de interesse das organizações, as quais passaram a ver as redes sociais virtuais como um amplo espaço para negociação de seus produtos e serviços, assim como visualizaram um potencial de relacionamentos, tendo este como forte capital social da atualidade (MACHADO; TIJIBOY, 2005). Mantovani e Santos Júnior (2013) analisaram a relação nas redes sociais, no que tange a geração de conteúdo, a criação de networking e as relações virtuais existentes nas comunidades do Orkut, identificando que o envolvimento do usuário será intensificado quanto maior for à relevância dos conteúdos gerados por essas comunidades virtuais.

Dentre as redes sociais mais utilizadas no Brasil destaca-se o Facebook. Segundo dados da própria rede social (FACEBOOK, 2017), quase metade da população mundial com acesso à Internet está conectada a esta rede social, o que representa um total de 1,7 bilhões de pessoas conectadas. Os usuários desta rede social podem participar de uma série de atividades e ações, tais como escrever em murais de amigos, comentar e compartilhar postagens e links, participar de fóruns de discussão e interagir com marcas por meio de uma opção denominada "curtir" (SMITH; FISCHER; YONGJIAN, 2012).

Diante disso, se a interação das atividades dos usuários pelas ações da própria marca for alta, implica em afirmar que há engajamento e poder-se-ia criar um potencial para gerar novo engajamento (FEITOSA; BOTELHO; LOURENÇO, 2014). Siqueira (2013, p. 18) é categórica ao afirmar que um consumidor engajado "possui mais valor para a empresa do que um comprador mediano, sem vínculos emocionais com a marca e, portanto, menos propenso a gerar conteúdos de forma espontânea".

Para Camargo Filho (2013), o engajamento online envolve o comprometimento em duas vertentes: afetiva e cognitiva. A primeira relacionada à afeição e/ou interesse sentido pelo usuário; e a segunda caracterizada pelo conhecimento gerado; ambas assinalam um relacionamento ativo com uma marca representada por um website ou outras formas eletrônica de apresentação. Mollen e Wilson (2010) asseguram que para o indivíduo o objeto virtual deve gerar dois tipos de valores: valores instrumentais, os quais dizem respeito à utilidade e relevância; e valores experimentais, que vão ao encontro de esquemas montados nos meios eletrônicos que são capazes de oferecerem um sentido emocional aos usuários.

Para esses autores, o envolvimento consiste na relação da atenção do indivíduo à tela. Logo, o engajamento surge quando, além do envolvimento "existe a intenção de interagir" (CAMARGO FILHO, 2013, p.20). Nesta perspectiva, o mesmo autor, afirma que o nível de engajamento é fortalecido na medida em que acontece a troca de informação e conhecimento sobre determinado assunto e/ou marca com outros participantes.

O termo "engajamento do consumidor" engloba, em sua maioria, às maneiras em que "os consumidores se envolvem com marcas através de canais digitais, como o site da marca, blogs, sites de redes sociais e vídeos" (JAYASINGH, VENKATESH, 2015, p. 20). Em estudo sobre a terminologia engajamento, realizado por Marra e Damacena (2013), observou-se que o termo engajamento é um conceito novo quando relacionado aos estudos na área de marketing, tendo em vista, que o interesse encontra-se na relação entre consumidores e empresas; outras disciplinas, por sua vez, já utilizam a terminologia para embasar seus estudos. Esses autores apontam que não há um consenso quanto ao conceito, pois há outros elementos envolvidos entorno do engajamento como: o engajamento da comunidade de marca, engajamento da propaganda e o engajamento do cliente. Diante disso, Camargo Filho (p. 14, 2013) explica que essa falta de consenso sobre o uso do termo faz com que "empresas invistam, sem sucesso, na busca do engajamento dos clientes justamente porque existe, entre eles, diferentes concepções sobre o que é estar engajado". 
Vivek et al. (2014) apresentam definições de engajamento pautadas pela holística do marketing, conforme apresentado no Quadro 1.

Quadro 1- Definições de Engajamento

\begin{tabular}{|c|c|c|}
\hline Autores & Definições & $\begin{array}{c}\text { Objeto/Termo } \\
\text { Usado }\end{array}$ \\
\hline $\begin{array}{l}\text { Vivek, Beatty } \\
\text { e Morgan } \\
(2012, \text { p.133) }\end{array}$ & $\begin{array}{l}\text { A intensidade em que há participação individual na conexão com as } \\
\text { ofertas da organização e/ou atividades organizacionais, em que ou o } \\
\text { consumidor ou a organização tenha iniciado. }\end{array}$ & $\begin{array}{l}\text { Engajamento do } \\
\text { consumidor }\end{array}$ \\
\hline $\begin{array}{l}\text { Mollen e } \\
\text { Wilson } \\
(2010, \text { p.922) }\end{array}$ & $\begin{array}{l}\text { O comprometimento cognitivo e afetivo do consumidor com a } \\
\text { marca como personificada pelo website ou outras entidades } \\
\text { mediadas pelo computador designadas para comunicar o valor da } \\
\text { marca. É caracterizada pelas dimensões dinâmicas e sustentáveis do } \\
\text { processo cognitivo e o valor instrumental satisfatório e valor } \\
\text { experimental. }\end{array}$ & $\begin{array}{l}\text { (Entidades online } \\
\text { ou mediadas por } \\
\text { computador) } \\
\text { Engajamento do } \\
\text { consumidor }\end{array}$ \\
\hline $\begin{array}{c}\text { Sashi } \\
(2012, \text { p.267) }\end{array}$ & $\begin{array}{l}\text { Engloba as experiências interativas do consumidor onde as TICs, } \\
\text { como as mídias sociais, agem como ferramentas que possibilitam e } \\
\text { facilitam tais experiências. O nível em que o consumidor engaja-se } \\
\text { com a empresa ou a comunidade virtual da empresa se dá de forma } \\
\text { que o compromisso seja efetivo e calculista. }\end{array}$ & $\begin{array}{l}\text { Processo de } \\
\text { Engajamento do } \\
\text { consumidor }\end{array}$ \\
\hline $\begin{array}{l}\text { Brodie et al. } \\
(2011 b, \text { p.60) }\end{array}$ & $\begin{array}{l}\text { "[Um] estado psicológico que ocorre através dos valores interativos, } \\
\text { experiências cocriativas do consumidor com um agente/objeto focal } \\
\text { (ex., uma marca) em serviços de relacionamento focal." }\end{array}$ & $\begin{array}{l}\text { Engajamento do } \\
\text { consumidor }\end{array}$ \\
\hline $\begin{array}{c}\text { Hollebeek } \\
(2011, \text { p.790) }\end{array}$ & $\begin{array}{l}\text { O nível em que o motivacional do consumidor,em que o estado } \\
\text { mental marca-relacionado e contexto-dependente é caracterizado } \\
\text { pelos níveis de atividades cognitivas, emocionais e } \\
\text { comportamentais quando interagido com a marca. Isso incluiu os } \\
\text { temas de imersão, paixão e ativação. }\end{array}$ & $\begin{array}{l}\text { Engajamento do } \\
\text { consumidor com a } \\
\text { marca }\end{array}$ \\
\hline $\begin{array}{l}\text { Gambetti, } \\
\text { Graffigna, e } \\
\text { Biraghi (2012, } \\
\text { p.668) }\end{array}$ & $\begin{array}{l}\text { O engajamento do consumidor com a marca aparece como um } \\
\text { conceito multi-dimensional combinando elementos como atenção, } \\
\text { diálogo, interação, emoções, prazer sensorial e ativação imediata } \\
\text { objetivando o desenvolvimento de uma experiência total entre } \\
\text { consumidor e marca. }\end{array}$ & $\begin{array}{l}\text { Engajamento de } \\
\text { propaganda/mídia, } \\
\text { relacionado ao } \\
\text { engajamento } \\
\text { entre cliente e } \\
\text { marca } \\
\end{array}$ \\
\hline $\begin{array}{l}\text { Van Doorn et } \\
\quad \text { al. } \\
(2010, \text { p.254) }\end{array}$ & $\begin{array}{l}\text { O comportamento de engajamento do consumidor vai além das } \\
\text { transações e são definidas como as manifestações comportamentais } \\
\text { do consumidor que tem uma marca ou uma empresa como foco, } \\
\text { que vai além da compra, resultado de alguns fatores motivacionais. }\end{array}$ & $\begin{array}{l}\text { Comportamento } \\
\text { de engajamento } \\
\text { do consumidor }\end{array}$ \\
\hline $\begin{array}{l}\text { Higgins e } \\
\text { Sholer } \\
(2009, \text { p.112) }\end{array}$ & $\begin{array}{l}\text { Um estado de envolvimento, ocupação, absorção completa, ou } \\
\text { comprometimento em alguma coisa (atenção dada), gerando como } \\
\text { consequência uma atração particular ou força de aversão. }\end{array}$ & $\begin{array}{c}\text { Força de } \\
\text { engajamento }\end{array}$ \\
\hline
\end{tabular}

Fonte: Vivek et al. (2014)

Em análise, observa-se que mesmo com o embasamento do marketing, há diferentes conceituação. Vivek, Beatty, Morgan (2012) compreendem o engajamento a partir da perspectiva do consumidor, entendendo este como uma ampliação do marketing de relacionamento. Brodie et al. (2011) destacam o envolvimento do cliente, que tange a relação de experiência interativa do consumidor e de criação de valor com a organização.

Para Hollebeek (2011) trata-se de um conceito com bases nas áreas de psicologia e comportamento organizacional, que acarreta na maior lealdade do cliente com a marca. Van Doorn et al. (2010), por sua vez, baseiam-se na relação entre empresa e consumidor sobre os aspectos comportamentais deste relacionamento. Os estudos e a conceituação de Van Doorn et al. (2010) 
para engajamento darão base para a realização deste trabalho. Assim, neste estudo, o engajamento será mensurado considerando três categorias: o período, a postagem e o retorno do fã.

\section{METODOLOGIA}

Dado o objetivo principal da pesquisa de descrever as atividades desenvolvidas por empresas de comércio eletrônico dentro das fanpages do Facebook e identificar o engajamento dos usuários, optou-se por adotar o método de observação sistemática direta (SANTOS; PINTO, 2016), através da extração dos dados das fanpages das três lojas brasileiras de comércio eletrônico que estivessem entre as cinco melhores do ranking Reclame Aqui (2014). O método de observação sistemática direta das fanpages utiliza para a extração dos dados um instrumento estruturado, seguindo indicação de Santos e Pinto (2016) e Aaker, Kumar e Day (2004, p. 233), de que esse tipo de observação "pode ser muito bem estruturada, com um formulário de registro detalhado preparado antecipadamente".

Quanto à abordagem da pesquisa, este estudo é quantitativo, através da coleta de dados secundários. O desenvolvimento quantitativo trata-se da quantificação de dados, de forma a possibilitar o cálculo de frequência, média, entre outros elementos estatísticos (MALHOTRA, 2006). Já no que tange aos dados secundários estes são dados produzidos pela empresa e que já estão disponíveis, seja através de dados que a empresa da amostra tenha produzido ou que estejam publicadas e armazenadas por outros meios (MALHOTRA, 2006).

A coleta de dados realizou-se em um período de cinco meses, contemplando o final de 2015 (setembro) e início de 2016 (janeiro) e as datas comemorativas consideradas comerciais do dia das crianças em outubro, Black Friday em novembro e Natal e Ano Novo em dezembro/janeiro. Como requisito para a seleção da amostra, escolheu-se três lojas brasileiras de comércio eletrônico que estivessem entre as cinco melhores do ranking Reclame Aqui (2014). Dessa forma, foram escolhidas como amostra a Submarino, Americanas.com e o Canal Shoptime, que além de se enquadrarem nas condições do estudo também fazem parte do mesmo grupo de empresas, a B2W Digital. Foram observadas todas as postagens durante o período de cinco meses nas páginas do Facebook das três lojas, totalizando 629 postagens para análise de dados.

\subsection{INSTRUMENTOS DE COLETA DE DADOS}

Para que a coleta seguisse as exigências de um estudo observacional, segundo Cooper e Schindler (2011), algumas especificações de verificação tiveram de ser criadas e conceituadas. Nesta lista de verificação serão conceituadas todas as categorias de dados que comporão o instrumento de coleta de dados. Os elementos foram selecionados a partir da literatura base desta pesquisa (PETRY; SIMONETTO, 2013; SILVA JR.; PEREIRA; CORREIA-NETO, 2013). Assim, a lista de verificação para a construção do instrumento de coleta está divido em três categorias:

- Período: essa categoria apresenta elementos que possibilitarão verificar as sazonalidades das postagens e encontrar a frequência de utilização das redes sociais pelas lojas virtuais;

- Postagem: os elementos desta categoria foram elaborados para identificar quais tipos de postagens são mais apresentadas pelas lojas virtuais e qual o conteúdo é mais abordado nas redes sociais;

- Retorno do Fã/Curtidor: através do número de curtidas, comentários e compartilhamentos essa categoria disponibilizará os dados necessários para verificar quais postagens estimulam e possuem maior grau de retorno por parte do usuário;

Estas categorias servem como norteadoras para a estruturação dos elementos a serem observados para a coleta de dados. A descrição exemplificada da lista de verificação com as categorias e os elementos que as compõe está disposta no Quadro 2: 
Quadro 2 - Elementos que compõem o instrumento de coleta de dados

\begin{tabular}{|c|c|c|}
\hline Categorias & Elementos & Descrição \\
\hline \multirow{3}{*}{ Período } & Frequência de postagens & \multirow{3}{*}{$\begin{array}{l}\text { A freqüência é determinada pelo número de postagens que a } \\
\text { empresa faz ao dia; o horário e o dia da semana em que mais é } \\
\text { feita a postagem }\end{array}$} \\
\hline & Horários de postagens & \\
\hline & Dia da se & \\
\hline \multirow[b]{2}{*}{ Postagem } & Tipo de postagem & \multirow{2}{*}{$\begin{array}{l}\text { O tipo de postagem descreve se a publicação é uma imagem, } \\
\text { vídeo, link, texto ou gif, enquanto o conteúdo engloba as } \\
\text { possibilidades de divulgação de promoções, produtos, informativos } \\
\text { ou não relacionado aos produtos e serviços da empresa. }\end{array}$} \\
\hline & Conteúdo da postagem & \\
\hline \multirow{3}{*}{$\begin{array}{l}\text { Retorno do } \\
\text { fã/seguidor }\end{array}$} & Número d & \multirow{3}{*}{$\begin{array}{l}\text { Verifica o retorno dos usuários que seguem/curtem a página da } \\
\text { loja através da quantificação do número de comentários, curtidas e } \\
\text { compartilhamentos de cada postagem. }\end{array}$} \\
\hline & $\begin{array}{c}\text { Número de } \\
\text { compartilhamentos }\end{array}$ & \\
\hline & Número de curtidas & \\
\hline
\end{tabular}

Fonte: Baseado em Petry e Simonetto(2013) e Silva Jr., Pereira e Correia-Neto (2013).

A partir dos elementos apresentados pelo Quadro 2 elaborou-se o instrumento de coleta de dados, estruturado como um formulário, conforme o Quadro 3:

Quadro 3 - Instrumento de coleta de dados

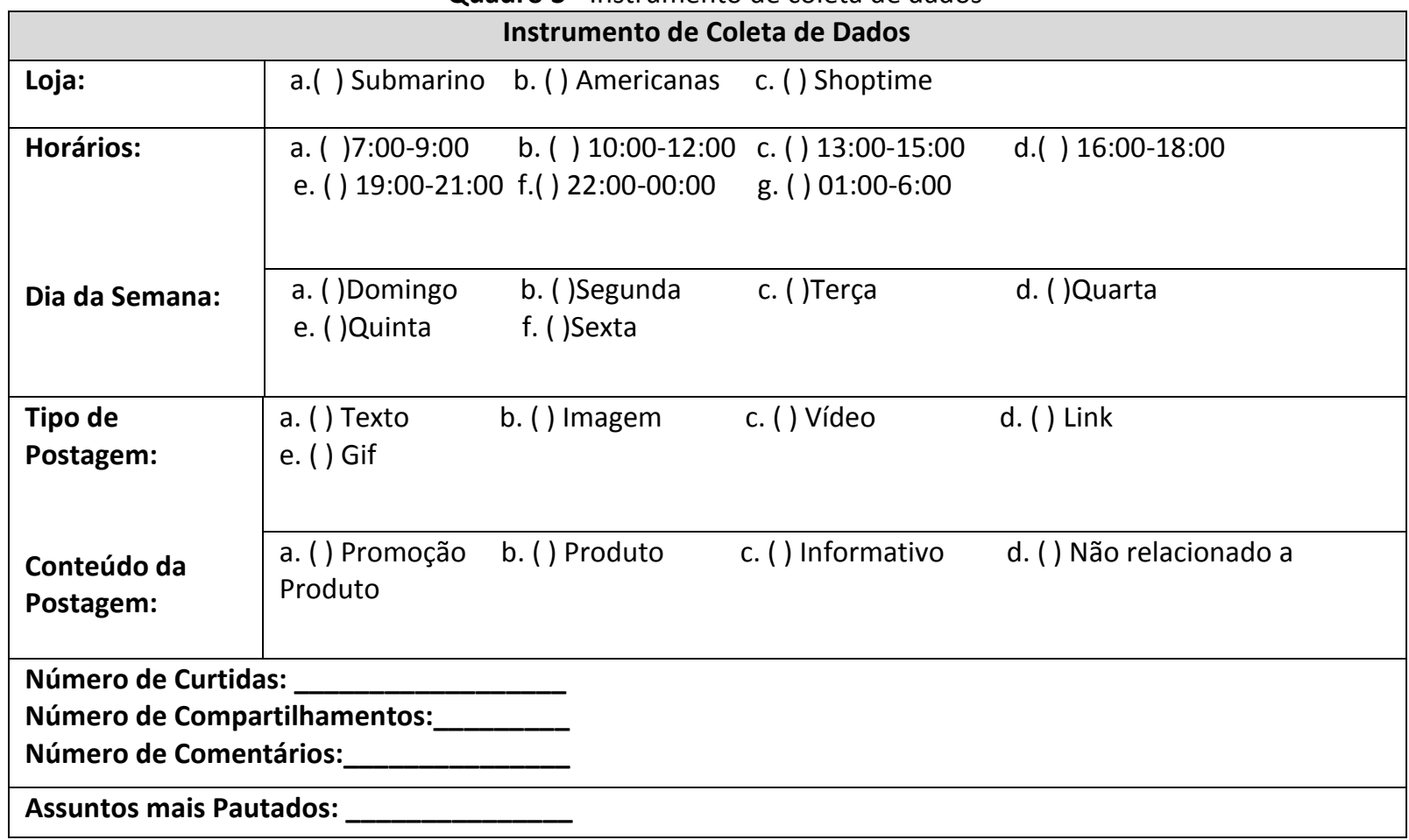

Fonte: Dados da pesquisa (2016)

Os dados coletados foram quantificados e armazenados com o auxílio do software Microsoft Excel. Quanto à análise dos dados esta pesquisa aplicará uma análise estatística descritiva, sendo os dados quantificados analisados através do software Statistical Package for the Social Sciences ${ }^{\mathrm{TM}}$ SPSS 21.0 versão livre para testes. Segundo Aaker, Kumar e Day (2004), a análise estatística utilizada neste estudo engloba a distribuição de frequência e medidas de posição (média, moda e mediana), são utilizadas para "oferecer números precisos, simples e significativos para sumarizar as informações de um grande conjunto de dados" (p. 450), exposto que vai ao encontro das

Perspectivas em Gestão \& Conhecimento, João Pessoa, v. 8, n. 1, p. 67-85, jan./abr. 2018. 
necessidades deste estudo para análise dos dados, uma vez que será coletado um número significativo de dados e pretende se alcançar respostas simples e diretas.

\section{ANÁLISES E DISCUSSÕES}

Em primeira instância, verifica-se o número de fãs (usuários que curtem e/ou seguem a página) que cada empresa deteve na rede social. A empresa com maior número de fãs é Americanas.com, que possuía 4.695.744 curtidas em sua página, seguida pela Submarino por uma diferença de 108 mil seguidores (4.587.677 curtidas), por fim, e com uma diferença nitidamente menor de seguidores vem o Canal Shoptime que possuía 1.156 .687 curtidas em sua página do Facebook.

Outra análise recai sobre o número total de postagens das lojas no período de cinco meses, bem como o número de dias em que não houve nenhuma publicação, conforme a Tabela 1:

Tabela1 - Postagens e faltas no período de cinco meses

\begin{tabular}{c|c|c}
\hline Lojas & $\begin{array}{c}\text { Número de } \\
\text { postagens no } \\
\text { período }\end{array}$ & $\begin{array}{c}\text { Número de dias } \\
\text { sem postagens }\end{array}$ \\
\hline Submarino & 219 & 11 \\
\hline Americanas & 126 & 44 \\
\hline Shoptime & 284 & 21 \\
\hline
\end{tabular}

Fonte: Dados da pesquisa (2016)

Quanto ao número de postagens verificadas no período, observou-se que a Shoptime obteve maior número de incidência de atividade, totalizando 284 postagens em 5 meses, seguida pela Submarino com 219 postagens e, por fim, a Americanas.com que obtivera um número de 126 postagens nos cinco meses de duração da pesquisa. Além disso, também se pôde avaliar o número de dias em que não houve nenhuma postagem na página das lojas. A Americanas.com teve maior hiato de dias sem postagens, totalizando 44 dias sem atividade na página, seguida pela Shoptime, que totalizou 21 dias sem postagens e por fim a Submarino, com 11 dias sem postagens.

Tabela 2 - Hora e Dia da semana das postagens das lojas no Facebook

\begin{tabular}{c|c|c|c|c}
\hline \multirow{4}{*}{} & \multicolumn{2}{|c|}{ Hora do Dia } & \multicolumn{2}{c}{ Dia da Semana } \\
\cline { 2 - 5 } & Hora & Percentual & Dia & Percentual \\
\hline \multirow{3}{*}{ Submarino } & $13: 00 \mathrm{~h}-15: 00 \mathrm{~h}$ & $42,2 \%$ & Sábado & $17,0 \%$ \\
\cline { 2 - 5 } & $19: 00 \mathrm{~h}-21: 00 \mathrm{~h}$ & $20,4 \%$ & Dominta-Feira & $14,8 \%$ \\
\cline { 2 - 5 } & $16: 00 \mathrm{~h}-18: 00 \mathrm{~h}$ & $9,6 \%$ & Sexta-Feira & $13,5 \%$ \\
\hline \multirow{3}{*}{ Americanas } & $19: 00 \mathrm{~h}-21: 00 \mathrm{~h}$ & $32,9 \%$ & Quinta-Feira & $13,5 \%$ \\
\cline { 2 - 5 } & $22: 00 \mathrm{~h}-00: 00 \mathrm{~h}$ & $17,1 \%$ & Quarta- Feira & $11,4 \%$ \\
\cline { 2 - 5 } & $16: 00 \mathrm{~h}-18: 00 \mathrm{~h}$ & $10,6 \%$ & Quarta-Feira & $17,7 \%$ \\
\hline \multirow{3}{*}{ Shoptime } & $13: 00 \mathrm{~h}-15: 00 \mathrm{~h}$ & $34,4 \%$ & Quinta-Feira & $16,4 \%$ \\
\cline { 2 - 5 } & $22: 00 \mathrm{~h}-00: 00 \mathrm{~h}$ & $20,7 \%$ & Segunda-Feira & $16,4 \%$ \\
\cline { 2 - 5 } & $19: 00 \mathrm{~h}-21: 00 \mathrm{~h}$ & $16,7 \%$ & & \\
\hline
\end{tabular}

Fonte: Dados da pesquisa (2016)

Observam-se na Tabela 2 os três dias da semana e horários com maior incidência de publicações no Facebook. É nítida a preferência das três lojas em postar na quinta-feira, uma vez que este dia está presente com a segunda maior percentagem na Submarino $(14,8 \%)$, na Americanas $(12,4 \%)$ e na Shoptime $(16,4 \%)$. A Quarta-feira também é dia predileto de postagens por parte da 
Americanas $(11,8 \%)$ e da Shoptime $(17,7 \%)$. É evidente que as publicações das lojas se concentram no período entre Quarta-feira a Domingo, com exceção da Shoptime que também tem preferência às Segundas-feiras $(16,4 \%)$.

Já quanto aos horários mais cotados estão os períodos das 19:00h às 21:00h, presente na Submarino com $20,4 \%$, na Americanas com $32,9 \%$ das vezes e na Shoptime com $16,7 \%$. Também o período entre 16:00h às 18:00h sendo de preferência da Submarino (9,6\%) e da Americanas (10,6\%). E por fim o período das $22: 00 \mathrm{~h}$ à meia noite, preferência da Americanas $(17,1 \%)$ e da Shoptime $(20,7 \%)$. Os horários em que se concentram as publicações das lojas virtuais provavelmente devemse ao fim do expediente convencional de trabalho, aumentando, dessa forma, as chances das pessoas verem as publicações em suas timelines.

Apesar de apresentar menor número de seguidores em sua página, o Canal Shoptime apresenta maior incidência de atividades na rede social, e um dos menores números de faltas dias/postagem. Entende-se que esta empresa pode estar esforçando-se mais para adquirir novos seguidores, enquanto a Americanas, com maior número de fãs concentra-se menos em na movimentação de sua página. Por sua vez, a Submarino encontra-se com alto número de curtidas na página e alto número de postagens e atividade. Percebe-se, também, por parte das três lojas que há concentração de publicações para o fim de semana e em horários fora do expediente de trabalho, potencializando assim, as chances de maior engajamento por parte dos clientes.

\subsection{Atividades exercidas pelas lojas no Facebook}

De modo a compreender como interagem as empresas na rede social, foi verificada a disposição do uso dos diferentes tipos de mídias do Facebook, como: imagens, vídeos, textos, gifs e links. A tabela 3 apresenta a frequência dos diferentes tipos de mídias utilizadas pelas lojas no Facebook:

Tabela 3 - Uso dos diferentes tipos de mídias no Facebook

\begin{tabular}{c|c|c|c|c|c|c}
\hline Lojas & Texto & Imagem & Vídeo & Link & Gif & Total \\
\hline Submarino & $10,30 \%$ & $42,70 \%$ & $8,70 \%$ & $37,20 \%$ & $1,10 \%$ & $100 \%$ \\
\hline Americanas & $8,90 \%$ & $35,40 \%$ & $16,50 \%$ & $38,70 \%$ & $1,20 \%$ & $100 \%$ \\
\hline Shoptime & $15,10 \%$ & $38,20 \%$ & $14,30 \%$ & $32,40 \%$ & $0,00 \%$ & $100 \%$ \\
\hline
\end{tabular}

Fonte: Dados da pesquisa (2016)

Verifica-se a proeminência do uso de imagens pela Submarino e Canal Shoptime, sendo que $42,70 \%$ das postagens da Submarino e $38,20 \%$ das postagens do Canal Shoptime são compostas por essa mídia. Muito provavelmente estas postagens vêm anexadas a algum link, uma vez que possui a segunda maior frequência de uso para ambas as lojas, sendo usadas em $37,20 \%$ das postagens da Submarino e $32,40 \%$ das do Canal Shoptime. Já para a Americanas.com o resultado deu-se ao inverso, onde $38,70 \%$ das postagens foram links, seguidos por $35,40 \%$ de imagens. As ferramentas menos usadas pelo comércio eletrônico são os gifs, sendo utilizado em apenas $1,20 \%$ das postagens da Americanas.com e 1,10\% das postagens da Submarino, não tendo nenhum incidência de uso pelo Canal Shoptime.

Este resultado conota a ideia de que a imagem chama maior atenção do usuário em sua timeline, e por isso é a mais utilizada pelas empresas de comércio eletrônico, além do mais a imagem não solicita grande tempo do usuário para entender e receber uma mensagem, de forma que se torna mais popular por sua simplicidade. Dondis (2003) assegura que os indivíduos compreendem melhor o que é transmitido através de uma imagem ou símbolo. Silva Jr, Pereira e Correia-Neto $(2013$, p. 150) expõem em seu trabalho que a preferência dos fãs das páginas por postagens do tipo

Perspectivas em Gestão \& Conhecimento, João Pessoa, v. 8, n. 1, p. 67-85, jan./abr. 2018. 
imagem pode estar "relacionada ao fato de imagens serem na maioria das vezes autoexplicativas e chamarem mais atenção.".

Aproveitando esta vantagem, o link geralmente é utilizado pelas lojas para direcionar o cliente ao site para realizar ou induzir à compra. De acordo com Limeira (2010) uma das formas mais utilizadas de divulgação da marca ou loja na internet é a criação de banners em sites de grande audiência e a realização de links em sites de busca como o Google. Logo, banners e links patrocinados são formas eficazes para a loja virtual conseguir tráfego virtual, ou seja, obter a visitação de um grande número de usuários.

Para uma compreensão das interações das lojas na rede social Facebook analisou-se o conteúdo de maior incidência postado por essas lojas, apresentando na Tabela 4 quatro diferentes conteúdos possíveis de postagem:

Tabela 4 - Conteúdo das postagens no Facebook

\begin{tabular}{c|c|c|c|c|c}
\hline Lojas & Promoções & Produtos & Informativo & $\begin{array}{c}\text { Não relacionado a } \\
\text { produtos }\end{array}$ & Total \\
\hline Submarino & $14 \%$ & $16,20 \%$ & $36,30 \%$ & $33,50 \%$ & $100 \%$ \\
\hline Americanas & $30,80 \%$ & $51,50 \%$ & $9,50 \%$ & $8,30 \%$ & $100 \%$ \\
\hline Shoptime & $24,80 \%$ & $40,60 \%$ & $20,50 \%$ & $14,20 \%$ & $100 \%$ \\
\hline
\end{tabular}

Fonte: Dados da pesquisa (2016)

É possível verificar bastante discrepância entre os conteúdos postados pelas três lojas. A Submarino, por exemplo, possui maior número de postagens Informativas (36,30\%) e Não relacionadas ao produto $(33,50 \%)$, do que as outras duas lojas, o que pode indicar que a Submarino não possui o foco de venda em suas postagens do Facebook. Ao contrário, na Americanas.com, $51,50 \%$ das postagens estão voltadas para os produtos oferecidos nas lojas e $30,80 \%$ apresentam algum tipo de promoção da loja. O Canal Shoptime possui o maior equilíbrio de postagens entre os quatro conteúdos apresentados, porém existe uma predominância de postagens voltadas para os produtos da loja $(40,60 \%)$.

Estes resultados indicam que as lojas Americanas.com e o Canal Shoptime tendem a utilizar mais a rede social Facebook como uma ferramenta de divulgação para seus produtos e promoções, enquanto a Submarino utiliza o canal de comunicação como uma forma de divulgar informativos não relacionados aos produtos e talvez entrar em contato com seus clientes de forma mais amigável. Segundo Batista (2011), as organizações estão fazendo uso das redes sociais virtuais como ferramenta de relacionamento de maneira que contribua na construção de suas marcas, sendo que o marketing virtual proporciona benefícios, tanto para o consumidor quanto para a empresa.

Os benefícios para o consumidor são os responsáveis para que o cliente seja fiel a marca e/ou organização. Dentre os benefícios pode-se destacar: "confiança, decorrente do conhecimento do consumidor para a empresa e vice-versa; social, o qual diz respeito ao envolvimento pessoal estabelecido; e tratamento especial" (BATISTA, 2011, p.41). Sheth, Parvatiyar e Sinha (2015, p. 120) alegam que os clientes tendem a se engajar em um relacionamento de longo prazo com as "organizações que proporcionam benefícios psicológicos e sociológicos conexos à redução do número de escolha de outras marcas ou empresas".

Como forma de avaliar os assuntos mais pautados pelas lojas, a Tabela 5 apresenta apenas os cinco mais frequentes utilizados pelas lojas: 
Tabela 5 - Assuntos mais pautados pelas lojas

\begin{tabular}{c|c|c|c|c|c}
\hline \multicolumn{2}{c|}{ Submarino } & \multicolumn{2}{c|}{ Americanas } & \multicolumn{2}{c}{ Shoptime } \\
\hline Assunto & $\begin{array}{c}\text { No de } \\
\text { vezes } \\
\text { citado }\end{array}$ & Assunto & $\begin{array}{c}\text { No de vezes } \\
\text { citado }\end{array}$ & $\begin{array}{c}\text { No de } \\
\text { vezes } \\
\text { citado }\end{array}$ \\
\hline Eventos & 82 & Produtos & 41 & Produtos & 64 \\
\hline Filmes & 25 & Black Friday & 24 & Receitas & 45 \\
\hline Promoção & 20 & Natal & 11 & Bom Dia & 31 \\
\hline Black Friday & 12 & Eventos & 10 & Black Friday & 14 \\
\hline Datas & 10 & Celulares & 7 & Natal & 12 \\
\hline Comemorativas & 10 & &
\end{tabular}

Fonte: Dados da pesquisa (2016)

Percebe-se que a Americanas.com e o Canal Shoptime abrangeram mais publicações acerca dos produtos vendidos, sendo o assunto citado 41 vezes pela Americanas.com e 64 vezes pelo Canal Shoptime. Enquanto a Submarino apresentou 82 postagens sobre eventos, como feira de livros, concertos, shows, bienais, etc., seguido por postagens sobre filmes (25 vezes). Entre os assuntos em comum das três empresas, a Black Friday se destaca, evento mundial de mega promoções que acontece na última sexta feira do mês de novembro, e que recebe atenção especial durante este período, sendo citado 12 vezes pela Submarino, 24 vezes pela Americanas.com e 14 vezes pelo Canal Shoptime. Ainda, cita-se o Natal pelas lojas Americanas.com (11 vezes) e Canal Shoptime (12 vezes), como mais um evento comercial para promoções.

É interessante ressaltar cada assunto de destaque das três lojas. Além de eventos, filmes e Black Friday, a Submarino também obteve grande incidência de postagens acerca de promoções da loja (20 citações) e avisos sobre datas comemorativas (10 citações). A Americanas.com também possuí maior quantidade de postagens referentes a eventos (10 citações) e novos modelos de celulares (7 postagens). Enquanto o Canal Shoptime preocupa-se com postagens de receitas, um dos produtos da loja que possui grande retorno por parte dos fãs da página, como percebido durante as observações. As receitas totalizaram 45 postagens. Outra preocupação da loja é sempre começar o dia com uma postagem de "bom dia" aos seguidores da página, com 31 citações.

Estes resultados reforçam a ideia de que a Submarino possui maior foco comunicativo com seus seguidores na rede social Facebook, enquanto a Americanas.com e o Canal Shoptime concentram-se em seus produtos e serviços, conforme observado na análise da Tabela 4.

\subsection{Engajamento do usuário com a loja}

O engajamento do usuário com as atividades desenvolvidas pelas empresas de comércio eletrônico se faz importante, uma vez que podem mensurar o sucesso que as lojas possuem em suas abordagens no Facebook. Dessa forma, também foi avaliado o engajamento do usuário com essas lojas, através da mensuração das médias de curtidas, comentários e compartilhamentos dados pelos usuários em suas postagens. Para que se possam observar as sazonalidades do sucesso das abordagens das empresas no Facebook, observou-se separadamente os meses de setembro de 2015 a janeiro de 2016 conforme Tabela 6: 
Tabela 6 - Engajamento dos usuários às lojas no período

\begin{tabular}{|c|c|c|c|c|c|c|c|}
\hline \multirow{2}{*}{ Lojas } & \multicolumn{5}{|c|}{ Média de curtidas do período } & \multirow{2}{*}{$\begin{array}{c}\text { Média } \\
\text { geral }\end{array}$} & \multirow[b]{2}{*}{ Total } \\
\hline & set./15 & out./15 & nov./15 & dez./15 & jan./16 & & \\
\hline Submarino & 134 & 92 & 187 & 74 & 150 & 127,4 & 637 \\
\hline Americanas & 270 & 210 & 259 & 206 & 334 & 255,8 & 1279 \\
\hline Shoptime & 1744 & 216 & 802 & 732 & 1124 & 923,6 & 4618 \\
\hline \multirow{2}{*}{ Lojas } & \multicolumn{5}{|c|}{ Média de comentários do período } & \multirow{2}{*}{$\begin{array}{c}\text { Média } \\
\text { geral }\end{array}$} & \multirow[b]{2}{*}{ Total } \\
\hline & set./15 & out./15 & nov./15 & dez./15 & jan./16 & & \\
\hline Submarino & 38 & 37 & 116 & 106 & 39 & 67,2 & 336 \\
\hline Americanas & 58 & 58 & 105 & 166 & 116 & 100,6 & 503 \\
\hline Shoptime & 93 & 1506 & 82 & 92 & 131 & 380,8 & 1904 \\
\hline \multirow[t]{2}{*}{ Lojas } & \multicolumn{5}{|c|}{ Média de compartilhamentos do período } & \multirow{2}{*}{$\begin{array}{c}\text { Média } \\
\text { geral }\end{array}$} & \multirow[b]{2}{*}{ Tota } \\
\hline & set./15 & out./15 & nov./15 & dez./15 & jan./16 & & \\
\hline Submarino & 10 & 8 & 21 & 8 & 58 & 21 & 105 \\
\hline Americanas & 12 & 15 & 14 & 12 & 25 & 15,6 & 78 \\
\hline Shoptime & 174 & 3995 & 125 & 149 & 754 & 1039,4 & 5197 \\
\hline \multirow{2}{*}{ Lojas } & \multicolumn{5}{|c|}{ Número de postagens do período } & \multirow{2}{*}{$\begin{array}{c}\text { Média } \\
\text { geral }\end{array}$} & \multirow[b]{2}{*}{ Total } \\
\hline & set./15 & out./15 & nov./15 & dez./15 & jan./16 & & \\
\hline Submarino & 84 & 34 & 32 & 32 & 37 & 43,8 & 219 \\
\hline Americanas & 29 & 29 & 33 & 19 & 31 & 28,2 & 141 \\
\hline Shoptime & 49 & 44 & 62 & 57 & 72 & 56,8 & 284 \\
\hline
\end{tabular}

Fonte: Dados da pesquisa (2016)

Observa-se que no mês de setembro de 2015 a loja Submarino obteve maior número de curtidas (134) do que comentários (38) e compartilhamentos (10). Além disso, foi a loja que apresentou maior número de postagens no período (84 postagens). Já a Americanas.com, mesmo sendo a loja que apresentou menos postagens (29), recebeu maior número de curtidas (270), comentários (58) e compartilhamentos (12) do que o Submarino.

O Canal Shoptime, por sua vez, foi à loja que obteve maior sucesso de interação com os usuários, mesmo não sendo a página que dispôs mais postagens (49 publicações), obtendo em média 1744 curtidas, 93 comentários e 174 compartilhamentos. Para Gummerus et al. (2012), devido ao expansivo número de usuários das redes sociais e suas características variadas, cada membro das comunidades de marca se relacionam com elas de uma maneira distinta. Logo, mesmo engajado com a marca, cada consumidor pode interagir de forma diferente com as comunidades e/ou grupos que mantém relação.

Contudo, apesar de diferentes formas de interação oferecidas - como comentar ou compartilhar publicações - estudo de Gummerus et al. (2012) evidencia que apenas uma pequena parcela de seus membros interagem com o conteúdo apresentado ou com outros participantes da comunidade. Os mesmos autores ainda concluíram que a "maioria dos usuários que utiliza a comunidade da marca como fonte de informação, ou seja, agir passivamente e apenas ler as mensagens é um comportamento predominante sobre aquele de ler ou expressar opiniões" (GUMMERUS et al., 2012, p. 05).

Quanto às médias de interações no mês de outubro de 2015, é possível perceber, outra vez, que a liderança de médias de curtidas (216), comentários (1506) e compartilhamentos (3995) foi do Canal Shoptime, que neste período também apresentou maior número de postagens (44). Seguido pela Americanas, que foi a segunda com melhores médias no período, e com 29 postagens, recebera em média 210 curtidas, 58 comentários e 15 compartilhamentos. Por último está a 
Submarino, que dispôs mais publicações que a Americanas (34 postagens), e que porém ainda apresenta a menor média de curtidas (92), comentários (37) e compartilhamentos (8).

No mês de novembro de 2015, o Canal Shoptime mais uma vez apresentou maior número de publicações (62) e maiores médias de curtidas (802) e compartilhamentos (125), porém obteve o menor número de comentários no período (82). A Americanas.com foi a segunda loja obter mais publicações (33), e apresentou a segunda melhor média de curtidas (259), tendo como médias de comentários e compartilhamentos 105 e 14, respectivamente. Neste período a Submarino apresentou menor número de publicações (32), porém obtivera a melhor média de comentários (116), e a segunda melhor média de compartilhamentos (21).

Em dezembro de 2015 percebe-se que o Canal Shoptime mantém-se como a loja com maior número de publicações (57) e melhores médias de curtidas (732) e compartilhamentos (149), porém possui a menor média de comentários (92) do período. A segunda loja a ter mais publicações foi a Submarino, porém foi a que obteve menores médias de curtidas (74), comentários (106) e compartilhamentos (8), enquanto a Americanas.com obteve as segundas melhores médias em curtidas (206) e compartilhamentos (12) e a melhor média das três lojas em comentários (166).

Por fim, em Janeiro de 2016 é possível verificar que o Canal Shoptime mantêm-se como a loja com mais número de publicações no mês (72). Além disso, é que a possui melhores índices de curtidas (1124), comentários (131) e compartilhamentos (754), seguida pela Americanas.com, com média de curtidas de 334 e compartilhamento de 116. No entanto, a Americanas.com foi à loja de comércio eletrônico que menos teve publicações (31 postagens) e menor índice de compartilhamentos (25). A Submarino obteve a segunda melhor média de compartilhamentos (58) e postagens (37) no período. Porém teve menor desempenho com a média de curtidas (150) e comentários (39).

Analisando cada loja separadamente durante os cinco meses, nota-se que o melhor desempenho de curtidas e comentários da Submarino foi no mês de novembro de 2015, com as médias de 187 e 116, respectivamente. Ainda, obteve mais compartilhamentos no mês janeiro de 2016, com uma média de 58, ainda que setembro fosse o mês em que mais havia publicado na página do Facebook.

Já a Americanas.com, obteve melhores índices de curtidas e compartilhamentos em janeiro de 2016, com uma média de 334 curtidas e 25 compartilhamentos. Já com os comentários, obteve mais sucesso em dezembro de 2015, com média de 166. O mês em que a Americanas.com mais dispôs de publicações foi novembro de 2015 (33 postagens).

O Canal Shoptime obteve maior média de curtidas em setembro de 2015 (1744), e média de 1506 comentários e 3995 compartilhamentos no mês de outubro de 2015. Para esta loja, o mês de janeiro de 2016 teve maior incidência de postagens (72 publicações).

De forma geral, conclui-se que o Canal Shoptime sobressai com relação às outras duas lojas em médias individuais de curtidas, comentários e compartilhamentos. Além disso, não pôde ser feita uma relação entre o número de postagens e as melhores médias de curtidas, comentários e compartilhamentos; uma vez que, não houve regularidade entre o número publicações e as médias de interação dos usuários; pode-se observar que alguns meses apresentam melhores médias desses índices não condizendo com o mês de maior publicação de todas as lojas.

Quando observado de forma geral as médias de todas as lojas é possível verificar que quanto às curtidas, comentários e compartilhamentos o Canal Shoptime possui uma evidente liderança, totalizando 4.618 curtidas, 1.904 comentários e 5.197 compartilhamentos ao longo dos cinco meses e ficando com uma média geral de 923,6 de curtidas, 380,8 comentários e 1.039,4 compartilhamentos. Mesmo sendo a página com menor número de fãs, consegue ultrapassar nitidamente o número de interações dos clientes das outras duas. Este fato aponta, para as outras duas lojas virtuais, a possibilidade de que a maioria dos membros dessa comunidade consuma os conteúdos de maneira passiva, assemelhando-se ao processo de lurking. De acordo com Kozinets (1999), esse processo pode ser entendido como uma atividade de navegação pouco atenta ao 
conteúdo disponibilizado, onde o usuário rola a página de conteúdo do website em questão de maneira desconcentrada e sem objetivo claro.

Na sequencia, a Americanas, com um total de 503 comentários e 1.279 curtidas, mas que não ultrapassa a Submarino em compartilhamentos e, por fim, a Submarino, com 336 comentários, 105 compartilhamentos e 637 curtidas. Observa-se, de forma geral, que o Canal Shoptime e a Americanas possuem um foco semelhante em suas atividades na rede social Facebook, procurando apresentar mais seus produtos e promoções, e buscando vender mais do que comunicar-se com os clientes através do canal de comunicação.

O Canal Shoptime possui o hábito de começar todos os dias com uma postagem de "bom dia" aos fãs, também concentra-se em postar mais receitas e produtos do que promoções, o que pode justificar o retorno e engajamento inflado dos usuários que os seguem. A Submarino visa na comunicação com o cliente, utilizando a rede social Facebook para falar de filmes e eventos, voltando-se para o relacionamento com seus seguidores. Contudo, mesmo utilizando uma abordagem diferente ela obteve a última colocação em índices de engajamento do cliente, liderando apenas na média de compartilhamentos.

\section{CONSIDERAÇÕES FINAIS}

A pesquisa realizada teve como objetivo descrever as atividades desenvolvidas pelas empresas de comércio eletrônico dentro das fanpages do Facebook; assim como, identificar o engajamento dos usuários para com as atividades desenvolvidas nas redes de relacionamento, de forma a verificar quais atividades gera maior engajamento por parte dos clientes. Observou-se que, diante das atividades exercidas pelas lojas no Facebook, as "imagens" aparecem como a ferramenta mais utilizadas, seguidas dos links.

Quanto ao conteúdo das postagens, nota-se que estes variam de acordo com o foco das empresas; no qual os produtos e as promoções são mais empregados pela Americanas.com e pelo Canal Shoptime, tendo em vista a comercialização dos artigos oferecidos por essas lojas. Já a Submarino tem como principal conteúdo de suas postagens os de cunho informativo, em sua maioria não vinculados aos produtos, mas à eventos que a empresa patrocina e/ou oferece cobertura.

No que tange ao engajamento do usuário com a loja, observou-se que as taxas de curtidas são superiores às de comentário que, por sua vez, superam as de compartilhamento; exceto, para o Canal Shoptime, o qual apresenta maior número de compartilhamentos que comentários. Isso pode indicar que os usuários buscam atividades que exijam menos esforço de sua parte quando utilizam as redes sociais. Outro aspecto relevante a ser pautado é quanto ao número de fãs e as interações, de forma que o Canal Shoptime, mesmo sendo a página com menor número de fãs, possui o maior número de comentários (33.238), curtidas (319.825) e compartilhamentos (251.977).

Acredita-se que essa resposta dos usuários seja pela maneira que a empresa se apresenta para o público, sendo que suas postagens instigam a participação do seguidor, ora respondendo um "bom dia", ora compartilhando uma receita. Logo, a variável "fãs" não representa ser um fator determinante para a criação de engajamento, mas sim, como pode-se observar, a comunicação e a interação com os usuários detém relação direta no retorno das fanpages.

Diante das análises percebe-se que quando uma organização deseja impressionar os seus fãs e consequentemente, abarcar novos, ela deve analisar as diversas variáveis envolvidas, a fim de responder às expectativas da maioria dos seus usuários; tendo em vista, que não há um gosto comum a todos, mas sim, que existem padrões que podem instigar e/ou proporcionar maior interação entre a organização e seus fãs (SILVA JR; PERREIRA; CORREIA-NETO, 2013).

Com relação às limitações da pesquisa, as aplicações das análises foram realizadas somente no período de cinco meses, impossibilitando a confirmação de um padrão de resultados. Além disso, foram analisadas apenas três lojas brasileiras de comércio eletrônico entre as melhores do ranking 
Reclame Aqui (2014), de modo que os resultados não podem ser generalizados a todas as lojas virtuais.

Para tanto, e visando a melhor compreensão do fenômeno do engajamento, é relevante que sejam realizados novos estudos, que levem em consideração demais meses do ano, inclusive com meses das diferentes épocas para a comparação dos resultados encontrados nesta pesquisa. Além disso, torna-se interessante considerar, o feedback das empresas para com os usuários no estudo do engajamento virtual, e também a motivação dos fãs para interagir com as páginas do Facebook.

\section{REFERÊNCIAS}

AAKER, D. A.; KUMAR, V.; DAY, G. S. Pesquisa de Marketing. 2. ed. São Paulo: Atlas, 2004.

ANDRADE, M. C. F. de; SILVA, N. T. G. da. Comércio eletrônico (e-commerce): um estudo com consumidores. Perspectivas em Gestão \& Conhecimento, João Pessoa, v. 7, n. 1, p. 98-111, jan./jun. 2017.

BATISTA, F. P. S. Gestão de marcas por meio das redes sociais: um estudo de caso sobre a utilização do Facebook. Dissertação (Mestrado em Administração de Empresas) - Programa de Pós-Graduação em Administração, Departamento de Administração, Faculdade de Economia, Administração e Contabilidade da Universidade de São Paulo, 2011. Disponível em: www.teses.usp.br/teses/disponiveis/12/12139/tde.../FlaviaPreussSiqueiraBatista.pdf. Acesso em: 20 jul. 2016.

BRODIE, R. J., ILIC, A.; JURIC, B.; HOLLEBEEK, L. Consumer engagement in a virtual brand community: An exploratory analysis. Journal of Business Research, v. 66, n. 1, Jan/2011. Disponível em: https://www.researchgate.net/publication/232957437 Consumer Engagement in a Virtual Brand Community An Exploratory Analysis. Acesso em: 04 mar. 2016.

CAMARGO FILHO, A. Em busca da melhor imagem: o impacto do tipo de post no engajamento e envolvimento do consumidor em comunidade virtuais de marca. 2013. 61f. Trabalho de Conclusão de Curso (Graduação)-Faculdade de Administração, Ciências Contábeis e Ciências Econômicas, Universidade Federal de Goiás, Goiânia, 2013. Disponível em: http://repositorio.bc.ufg.br/handle/ri/4261. Acesso em: 23 fev. 2016.

COOPER, D. R.; SCHINDLER, P. S. Métodos de Pesquisa em Administração. 10. ed. Porto Alegre: Bookman, 2011.

DACOL, C. C.; SILUK, J. C. M.; NEUENFELDT JÚNIOR, A. L.; SOLIMAN, M. Mensuração da competitividade em instituições de ensino superior privadas com base nas redes sociais digitais. Perspectivas em Gestão \& Conhecimento, João Pessoa, v. 4, Número Especial, p. 96-108, out. 2014

DONDIS, D. Sintaxe da linguagem visual. São Paulo: Martins Fontes, 2003. Disponível em: https://pt.scribd.com/document/62280768/Donis-Dondis-2003-sintaxe-Da-Linguagem-Visual. Acesso em: 26 jul. 2016.

FACEBOOK, 2017. 6 razões que mostram que o Facebook e o Instagram são plataformas criativas. Disponível em: https://pt-br.facebook.com/business/news/6-razoes-que-mostram-que-o-facebooke-o-instagram-so-plataformas-criativas. Acesso em: 07 dez. 2017. 
FEITOSA, W. R.; BOTELHO, D.; LOURENÇO, C. E. Comunidades virtuais de marca de produtos de consumo e criação de engajamento: uma investigação qualitativa. Revista Eletrônica Gestão e Serviço, v. 5, n. 1, 2014. Disponível em: https://www.metodista.br/revistas/revistasims/index.php/REGS/article/view/4852/4254. Acesso em: 02 mar. 2016.

FIALHO, J. M. R. Análise de redes sociais: princípios, linguagem e estratégias de ação na gestão do conhecimento. Perspectivas em Gestão \& Conhecimento, João Pessoa, v. 4, Número Especial, p. 926, out. 2014.

GLOBO.COM. Facebook completa 10 anos; veja a evolução da rede social. Disponível em: http://g1.globo.com/tecnologia/noticia/2014/02/facebook-completa-10-anos-veja-evolucao-da-redesocial.html. Acesso em: 27 fev. 2016.

GUMMERUS, J.; LILJANDER, V.; WEMAN, E.; PIHLSTRÖM, M. Customer engagement in a Facebook brand community. Management Research Review, v. 35, n. 9, 2012. Disponível em: < https://marketing.conference-services.net/resources/327/3554/pdf/AM2013_0340_paper.pdf>. Acesso em: 01 jul. 2016.

HOLLEBEEK, L.D. Demystifying customer brand engagement: exploring the loyalty nexus. Journal of Marketing Management, v. 27, n.7/8, p. 785-807, 2011. Disponível em: file:///C:/Users/User/Downloads/Demystifying customer brand engagement Exploring.pdf.

Acesso em: 23 abr. 2016.

JAYASINGH, S.; VENKATESH, R. Customer Engagement Factors in Facebook Brand Pages. Asian Social
Science,
11 ,
n. 26,
2015.
Disponível
em:

http://www.ccsenet.org/journal/index.php/ass/article/viewFile/50815/28200. Acesso em:

03 mar. 2016.

KOZINETS, R. On Netnography: Initial Reflections on Consumer Research Investigations of Cyberculture. In: ALBA, J; HUTCHINSON, W. (ed.). Advances in Consumer Research, Provo, UT: Association for Consumer Research, p. 366-371, 1998. Disponível em: http://www.acrwebsite.org/search/view-conference-proceedings.aspx?ld=8180. Acesso em: 01 jul. 2016.

LIMA, V. M.; NUNES, J. M. G. Engajamento do Consumidor em uma Comunidade Virtual de Marca. ENCONTRO DE MARKETING DA ANPAD, 8., 2015, Curitiba. Anais eletrônicos... Associação Nacional de Pós-Graduação e Pesquisa em Administração, Curitiba 2015. Disponível em: http://www.anpad.org.br/ anpad/abrir pdf.php?e=MjAzMjl=. Acesso em: 16 mar. 2016.

LIMEIRA, T. M. V. E-marketing: o marketing na internet com casos brasileiros. 2. ed. São Paulo: Saraiva, 2010.

MACHADO, J. R.; TIJIBOY, A. V. Redes Sociais Virtuais: um espaço para efetivação da aprendizagem cooperativa. Novas Tecnologias na Educação - CINTED-UFRGS, Porto Alegre, v. 3, n. 1, mai. 2005. Disponível em: http://www.seer.ufrgs.br/renote/article/viewFile/13798/7994. Acesso em: 08 dez. 2017.

MALHOTRA, N. K. Pesquisa de Marketing: uma orientação aplicada. 4. ed. Porto Alegre: Bookman, 2006. 
MANTOVANI, D. M. N.; SANTOS JÚNIOR, D. L. Relações nas redes sociais: geração de conteúdo, criação de networking e projeção das relações virtuais nas comunidades do Orkut. Revista de Administração e Inovação, v.10, n.3, 2013.

MARRA, G. S.; DAMACENA, C. Engajameno do consumidor: revisão teórica do conceito e seus antecedentes. Revista de Gestão, v. 20, n. 2, 2013.

MOLLEN, A.; WILSON, H. Engagement, Telepresence and Interactivity in Online Consumer Experience: Reconciling Scholastic and Managerial Perspectives. Journal of Business Research, v. 63, n. 9-10, 0.010 .2019 Disponível https://dspace.lib.cranfield.ac.uk/bitstream/1826/7475/1/Engagement Telepresence and Interacti vity.pdf. Acesso em: 28 mar. 2016.

MUSSUCHIN, M. G.; TAVARES, C. Q. Cobertura da Greve Paranaense no Facebook: engajamento dos leitores na Página do Gazeta do Povo. Revista FAMECOS mídia, cultura e tecnologia, v.23, n.2, 2015.

OFCOM, Office of Communications. Social Networking A quantitative and qualitative research report into attitudes, behaviours and use. 2008. Disponível em: http://news.bbc.co.uk/2/shared/bsp/hi/pdfs/02 0408 ofcom.pdf. Acesso em: 21 mar. 2016.

OKADA, S. I. Web analytics: modelos de métricas de engajamento em mídias emergentes. Revista Brasileira de Marketing, v.10, n. 3, 2011. Disponível em: http://www.revistabrasileiramarketing.org/ojs-2.2.4/index.php/remark/article/view/2271. Acesso em: 17 mar. 2016.

OVIEDO-GARCÍA, M. A.; EXPÓSITO, M. M.; VERDUGO, M. C.; MEJÍAS, M. S. Metric proposal for customer engagement in Facebook. Journal of Research in Interactive Marketing, v. 8, n. 4, p.327 44, 2014. Disponível em: http://dx.doi.org/10.1108/JRIM-05-2014-0028. Acesso em: 29 mar. 2016.

PETRY, A. C.; SIMONETTO, E. O. Uso do Twitter como Canal de Marketing: Uma Análise das Principais Empresas Brasileiras de Comércio Eletrônico. Sistemas \& Gestão Revista Eletrônica, Santa Maria, v. 8, n. $1, \quad$ p. 94-104, 2013. Disponível em: http://www.revistasg.uff.br/index.php/sg/article/viewFile/V8N1A9/V8N1A9. Acesso em: 23 maio 2016.

RAPP, A.; BEITELSPACHER, L. S.; GREWAL, D.; HUGHES, D. E. Understanding social media effects across seller, retailer, and consumer interactions. Journal of the Academy of Marketing Science, v. 41, n. 5, 2013. Disponível em: http://link.springer.com/article/10.1007/s11747-013-0326-9\#/page-1. Acesso em: 03 mar. 2016.

RECLAME AQUI. Confira a Lista das 30 Piores e Melhores Lojas que Vendem pela Internet. 2014. Disponível em: http://www.reclameaqui.com.br/noticias/noticias/confira-lista-das-30-melhores-epiores-lojas-que-vendem-pela 815/. Acesso em: 08 abr. 2016. 
SHAWHENEY, M.; VERONA, G.; PRANDELLI, E. Collaborating To Create: The Internet A Platform For Customer Engagement In Product Innovation. Journal of Interactive Marketing, v. 19, n. 4, 2005.Disponível

em:

https://www.researchgate.net/profile/Mohanbir Sawhney/publication/227606685 Collaborating t o create The Internet as a platform for customer engagement in product innovation/links/0c 960534690ff0296c000000.pdf. Acesso em: 10 mar. 2016.

SECOM - Secretaria de Comunicação Social. Pesquisa brasileira de mídia 2015: hábitos de consumo de mídia pela população brasileira. Brasília: Secom, 2014. Disponível em: http://www.secom.gov.br/atuacao/pesquisa/lista-de-pesquisas-quantitativas-e-qualitativas-decontratos-atuais/pesquisa-brasileira-de-midia-pbm-2015.pdf. Acesso em: 12 maio 2016.

SEDLEY, R. Six theses on digital customer engagement in a troubled economy. 2008. Disponível em: https://www.academia.edu/1892729/Six Theses on Digital Customer Engagement in a Troubled Economy. Acesso em: 20 maio 2016.

SANTOS, D. C. dos; PINTO, J. C. de P. Utilização de medidas de centralidade na análise de redes sociais online contextualizada na Interatividade entre marcas e consumidores. Revista Perspectivas Contemporâneas, v. 11, n.1, p. 140-164, jan./abr. 2016.

SILVA JÚNIOR, A. P.; PERREIRA, F. A.; CORREIA-NETO, J. da S. Engajamento digital: um estudo com páginas de instituições de ensino superior no Facebook. Revista Brasileira de Administração Científica, v.4, n.2, 2013.

SIQUEIRA, O. A. S. Publicidade lúdica: um estudo sobre engajamento digital em jogos sociais. 2013. Dissertação (Mestrado em Comunicação) - Universidade Federal de Pernambuco, CAC. Comunicação, $2013 . \quad$ Disponível em: http://repositorio.ufpe.br/bitstream/handle/123456789/10517/disserta\%c3\%a7\%c3\%a3o\%20olga\%20 siqueira.pdf?sequence=1\&isallowed=y. Acesso em: 01 mar. 2016.

SMITH, A. N., FISCHER, E.; YONGJIAN, C. How does brand-related usergenerated content differ across Youtube, Facebook, and Twitter. Journal of Interactive Marketing, v.26, n.2, p.102-113, 2012.

SOARES, F. R.; MONTEIRO, P. R. R. Marketing digital e marketing de relacionamento: interação e engajamento como determinantes do crescimento de páginas do Facebook. NAVUS - Revista de Gestão e Tecnologia, Florianópolis, v. 8, n. 3, p. 42-59 ; Jul./set. 2015.

SOCIALBAKERS. Facebook statistics directory. Disponível em: http://www.socialbakers.com/statistics/facebook/. Acesso em: 20 maio 2016.

SHETH, J. N.; PARVATIYAR, A.; SINHA, M.. The Conceptual Foundations of Relationship Marketing: Review and Synthesis. Journal of Economic Sociology Ekonomicheskaya sotsiologiya, v. 16, n. 2, p. 119-149, 2015.2 Disponível em: https://ecsoc.hse.ru/data/2015/03/30/1095767324/ecsoc t16 n2.pdf\#page=119. Acesso em: 14 jul. 2016.

TELLES, A. A revolução das mídias sociais. Cases Conceitos, dicas e ferramentas. Editora M. Books, 2010. Disponível em: http://www.andretelles.net.br/downloads/a-revolucao-das-midias-sociaisandre-telles.pdf. Acesso em: 27 fev. 2016. 
VAN DOORN, J., LEMON, K. N., MITTAL, V., NASS, S., PICK, D., PIRNER, P., e VERHOEF, P. C. Customer Engagement Behavior: Theoretical Foundations and Research Directions. Journal of Service Research, v. 13, n.3, p. 253-66, 2010. Disponível em: http://jsr.sagepub.com/content/13/3/253.full.pdf+html. Acesso em: 01 mar. 2016.

VIVEK, S. D; BEATTY, S. E.; MORGAN, R.M. Customer Engagement: Exploring Customer Relationships Beyond Purchase. The Journal of Marketing Theory and Practice, v. 20, n. 2, p.127-45, 2012. Disponível em: https://www.researchgate.net/publication/279714771 Customer Engagement Exploring Customer Relationships Beyond Purchase. Acesso em: 13 fev. 2016.

VIVEK, S. D.; BEATTY, S. E,; DALELA,V.; MORGAN, R. M. A Generalized Multidimensional Scale for Measuring Customer Engagement. Journal of Marketing Theory and Practice, v. 22, n. 4, 2014. Disponível em: http://dx.doi.org/10.2753/MTP1069-66792220404. Acesso em: 29 fev. 2016. 